\title{
Overweight/obesity among school aged children in Bahir Dar City: cross sectional study
}

Teferi Mekonnen ${ }^{1 *}$, Amare Tariku² and Solomon Mekonnen Abebe $^{2}$

\begin{abstract}
Background: Developing countries, including Ethiopia are experiencing a double burden of malnutrition. There is limited information about prevalence of overweight/obesity among school aged children in Ethiopia particularly in Bahir Dar city. Hence this study aimed to assess the prevalence of overweight/obesity and associated factors among school children aged 6-12 years at Bahir Dar City, Northwest Ethiopia.

Methods: A school based cross-sectional study was carried out. A total of 634 children were included in the study. Multi stage systematic random sampling technique was used.

A multivariable logistic regression analysis was used to identify factors associated with overweight/obesity. The association between dependent and independent variables were assessed using odds ratio with $95 \%$ confidence interval and $p$-value $\leq 0.05$ was considered statistically significant.

Results: The overall prevalence of overweight and/or obesity was $11.9 \%(95 \% \mathrm{Cl}, 9.3,14.4)$ (out of which $8.8 \%$ were overweight and 3.1\% were obese). Higher wealth status[adjusted $\mathrm{OR}=3.14,95 \% \mathrm{Cl}: 1.17,8.46]$, being a private school student [AOR $=2.21,95 \% \mathrm{Cl}: 1.09,4.49]$, use of transportation to and from school [AOR $=2.53,95 \% \mathrm{Cl}: 1.26,5.06]$, fast food intake $[A O R=3.88,95 \% \mathrm{Cl}: 1.42,10.55]$, lack of moderate physical activity $[A O R=2.87,95 \% \mathrm{Cl}: 1.21,6.82]$, low intake of fruit and vegetable $[A O R=6.45,95 \% \mathrm{Cl}: 3.19,13.06]$ were significant factors associated with overweight and obesity.

Conclusion: This study revealed that prevalence of overweight/obesity among school aged children in Bahir Dar city is high. Thus, promoting healthy dietary habit, particularly improving fruit and vegetable intake is essential to reduce the burden of overweight and obesity. Furthermore, it is important to strengthen nutrition education about avoiding junk food consumption and encouraging regular physical activity.
\end{abstract}

Keywords: Overweight, Obesity, School aged children, Body mass index for age, Ethiopia

\section{Background}

Overweight/obesity is defined as abnormal or excessive fat accumulation that may impair health [1]. There is a substantial increase in prevalence of overweight/obesity among children and adolescents in both developed and developing countries [2]. Worldwide 43 million children were overweight/obese and, of which 35 million children are from developing countries. In addition, 92 million were found at risk of having overweight and obesity [3]. Studies done in developed countries revealed that the

\footnotetext{
* Correspondence: tmekonnen16@yahoo.com

${ }^{1}$ Public Health Nutrition unit, School of Public Health, Bahir Dar University,

P.O. Box 79, Bahir Dar, Ethiopia

Full list of author information is available at the end of the article
}

prevalence of overweight/obesity among school children is increasing [4-6].

In Africa, despite that there has been a higher burden of under nutrition, the magnitude of overweight and obesity is increasing at an alarming rate [2, 7-9]. In SubSaharan Africa, about $10.6 \%$ of school aged children were overweight/obesity, of which $2.5 \%$ were obese [10]. Pocket studies done in Tanzania and Kenya showed that the prevalence of overweight and obesity is also increasing in these two countries [11-13].

In Ethiopia, pocket studies done in Addis Ababa among school adolescent revealed that about $7.6-9.9 \%$ of school adolescent were overweight, while $0.9-2.8 \%$ were obese $[14,15]$. 
Childhood obesity poses a major risk for serious dietrelated chronic diseases, such as type 2 diabetes mellitus, cardiovascular disease, hypertension and stroke, and certain forms of cancer and, it is also noted to be a precursor of adverse health effects in adulthood, as overweight children are more likely to become overweight adolescents and adults [8, 16, 17]. Globally, an estimated 3.4 million deaths, 3.9\% years of life lost, and 3.8\% of Disability Adjusted Life Years (DALYs) are related to overweight and obesity [2]. The rising of overweight/obesity epidemics is attributed by rapid economic and epidemiologic transition, caused by several socioeconomic and demographic changes that reflects the profound changes in the society $[7,13,18,19]$.

In addition, overweight and obesity is favored by risky dietary behaviors such as consumption of fast food and drinks, eating away from home, skipping/missing of meal, regular drinking of sugar rich beverages and low serving/ intake of fruit and vegetable [20-23]. In countries with limited resources and food availability, childhood overweight/obesity is favored by the good socioeconomic status of their parents while still insufficient nutrition education is available [24]. Eating behavior of the children is influenced by the availability of food, peers, siblings and parent's behavior [25]. Sedentary behavior and physical inactivity are also important risk factors for childhood overweight and obesity [26].

Now days in Ethiopia the focus agenda is under nutrition, but there are evidences for nutrition transition particularly in urban cities which might have a contribution to over nutrition. In Ethiopia, particularly in the study area, there was no information regarding prevalence and contributing factors of overweight/ obesity among school aged children, though it is known that early prevention of childhood obesity improves quality of life by decreasing an insult for chronic diseases for adolescent and adulthood life. Hence, it is important to assess the prevalence and associated factors of overweight/obesity among school aged children at the capital city of Amhara region, Bahir Dar city.

\section{Methods}

\section{Study setting and population}

This school based cross-sectional study was conducted from February 1st to April 15th, 2016 among first cycle elementary school students aged 6-12 years at Bahir Dar City. The city is the capital of Amhara National Regional State, which is situated in northwest Ethiopia. The city has 64 first cycle elementary schools of which 38 are public and 26 are private schools, with a total of 28,088 students. Of the total students, 6155 students were attending private schools while 21,933 were studying at public schools [27].

\section{Sample size and sampling procedures}

Sample size was calculated using single proportion formula by considering the following assumptions: the prevalence of overweight/obesity among school aged children (6-12 years) was unknown and taken as 50\%, margin of error of 5\%, confidence level of 95\%, $10 \%$ none-response rate, and a design effect of 1.5 . The final sample size was 634 .

A multi stage sampling technique was carried out. Primary sampling units were selected public and private schools. By taking $20 \%$ of both public and private school provides eight public and five private schools were included in the study. Lottery method was used to select schools, for each selected school, the samples were allocated proportional to number of students with respect to grade level. The secondary sampling unit was randomly selected students from each selected grade and section. Proportional allocation of the sample to the total number of students in each public and private were made and 139 students from private school and 495 students from public school with total of 634 students were included in the study using systematic random sampling technique.

\section{Data collection instrument and procedure}

Structured pre-tested questionnaire adapted from the WHO stepwise questionnaire for Chronic Disease Risk Factor Surveillance were used for data collection [28]. The questionnaire was prepared in English first and then translated to local language, Amharic, and back to English by public health experts. Five clinical nurses as data collectors and two BSc nurses as supervisors were trained for data collection and supervision. Anthropometric measurements were done by trained data collectors using standard procedures and calibrated equipment.

The anthropometric assessment was done according to the standardized procedures stipulated by the Food and Nutrition Technical Assistance (FANTA) 'Anthropometric Indicators Measurement Guide [29].

Height was measured to the nearest $0.1 \mathrm{~cm}$ in standing position at Frankfurt plane with the occipital, shoulder and the buttock touches the vertical stand using a stadiometer seca (Germany). Weight was measured to the nearest $0.1 \mathrm{~kg}$ using electronic weighing scale with wearing light clothes and with no shoes. The Percentile values for BMI-for-age (BAZ) of children were generated from WHO AnthroPlus version 1.0.3 software [30].

Overweight/obesity in school aged children were considered as dependant variable. BMI for age greater than or equal to 85th but less than 95th percentile was considered as overweight, while obesity was considered when BMI for age was greater than or equal to the 95th percentile [31]. 


\section{Data quality control}

For data quality control a pre-test on $5 \%$ of the samples was performed and regular supervision during data collection was also carried out. The completeness of the questionnaire was checked before data entry too.

\section{Data processing and analysis}

The data were first coded and entered using EpiData statistical software version 3.1 and then exported into SPSS statistical software version 20 for data management and analysis. Descriptive statistical analysis, such as simple frequencies and measures of central tendency was used to describe the characteristics of participants. Magnitude of overweight/obesity were determined by exporting age, sex, height, weight of the child to WHO AnthroPlus from SPSS software. Household wealth status was estimated using Household wealth index (HWI) constructed by using Principal Component Analysis (PCA) and the component score coefficient matrix was computed based on household assets then the households were categorized into tertiles according to the HWI as poor, middle income, high income.

Crud odds ratio with $95 \%$ CI was used to see the association between each independent variable and the outcome variable by using Binary logistic regression. Those associations with $p$-value $<0.2$ were entered into the multivariable logistic regression model to control the effect of confounding. Variables with a p-value less than 0.05 were taken as statistically significant associated factors. The adjusted odds ratio with 95\% confidence interval was presented to show the strength and precision of the association.

\section{Results}

\section{Socio-demographic and economic characteristics}

A total of 616 children participated, with a response rate of $97.2 \%$. Of the total, 483 (78.4\%) were attending public schools. 339 (55\%) children were female. The mean age of the children was $9.7 \pm 1.4$ years. $519(84.3 \%)$ mothers were married and $475(88 \%)$ attended formal education. 321 (52.1\%) and 224(36.4\%) of fathers and mothers were self employed, respectively (Table 1 ).

Type of school the students enrolled by the household's wealth status

A substantial variation in the type of school enrollment was observed in the lowest and highest household's wealth status category. Accordingly, about 41.4 and $4.51 \%$ of children from the lowest wealth status attended public and private schools, respectively. On the other hand, nearly two-third (67.67\%) and one-quarter $(24.22 \%)$ of children of the highest wealth status households were enrolled at private and public schools, respectively (Fig 1).
Table 1 Socio-demographic characterstics of parents and children aged 6-12 years in Bahir Dar City northwest Ethiopia, $(n=616)$

\begin{tabular}{|c|c|c|}
\hline Variables & Frequency & Percentage \\
\hline \multicolumn{3}{|l|}{ Marital status respondent } \\
\hline Single & 8 & 1.3 \\
\hline Married/partner & 519 & 84.3 \\
\hline Divorced/separated & 54 & 8.8 \\
\hline Widowed & 35 & 5.7 \\
\hline \multicolumn{3}{|l|}{ Maternal religion } \\
\hline Orthodox & 500 & 81.2 \\
\hline Muslim & 86 & 14.0 \\
\hline Catholic & 8 & 1.3 \\
\hline Protestant & 20 & 3.2 \\
\hline Others & 2 & 0.3 \\
\hline \multicolumn{3}{|l|}{ Educational status of the mother } \\
\hline No Formal Education & 141 & 22.9 \\
\hline Primary Education & 158 & 25.6 \\
\hline Secondary education \&Above & 317 & 51.5 \\
\hline \multicolumn{3}{|l|}{ Educational status of the father } \\
\hline No Formal Education & 124 & 20.1 \\
\hline Primary Education & 127 & 20.6 \\
\hline Secondary education \&Above & 365 & 59.3 \\
\hline \multicolumn{3}{|l|}{ Fathers occupation } \\
\hline private employed & 321 & 52.1 \\
\hline Formally Employed & 237 & 38.5 \\
\hline Daily laborer & 58 & 9.4 \\
\hline \multicolumn{3}{|l|}{ Mothers occupation } \\
\hline Private Employed & 224 & 36.4 \\
\hline Formally Employed & 131 & 21.3 \\
\hline Daily laborer & 41 & 6.7 \\
\hline Housewife & 220 & 35.7 \\
\hline \multicolumn{3}{|l|}{ Respondent sex } \\
\hline Male & 70 & 11.4 \\
\hline Female & 546 & 88.6 \\
\hline \multicolumn{3}{|l|}{ Child sex } \\
\hline Male & 277 & 45 \\
\hline Female & 339 & 55 \\
\hline \multicolumn{3}{|l|}{ Type of school } \\
\hline Public & 483 & 78.4 \\
\hline Private & 133 & 21.6 \\
\hline
\end{tabular}

\section{Dietary habit}

Regarding the dietary pattern of the children, 347 (56.3\%) school aged children consumed both fruit and vegetable, 324 (52.6\%) had snacks, 51.2\% two times per week or less. With regard to meal frequency, 593 (96.3\%) took meal for three times or more, and about 


\section{$67.67 \%$}

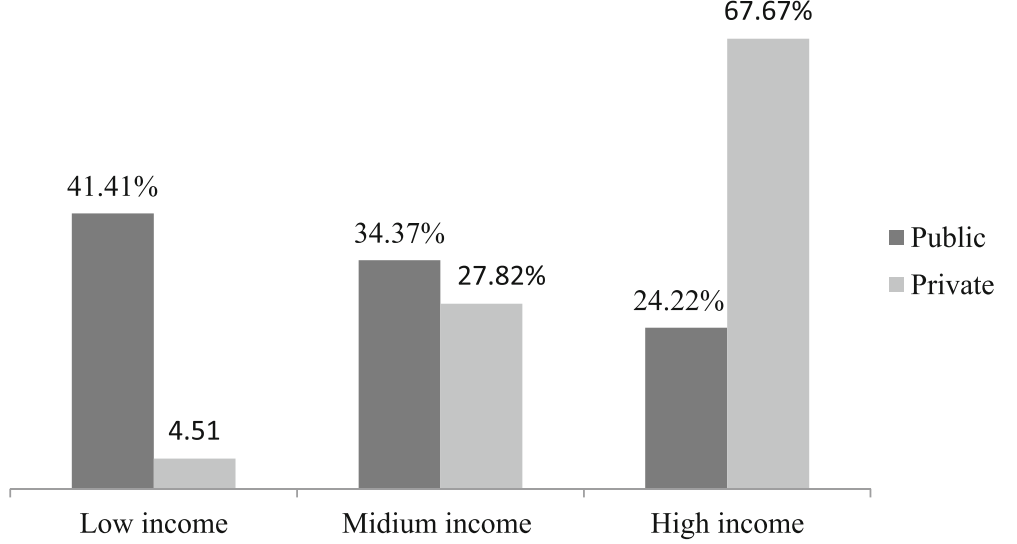

Fig. 1 Type of school enrolment stratified by household wealth status among school children in Bahir Dar city, 2016

$76.8 \%$ had bought and used either one or more of this food list(biscuit, chocolate, ice-cream or cake) listed under fast food intake. 285(46.3\%) watches television while eating. Furthermore, 268(43.5\%) had a habit of missing meals and $341(56.7 \%)$ had access to the restaurant/shop for fast food (Table 2).

\section{Physical activity and sedentary behavior related characteristics}

Regarding physical activity and sedentary behavior, the majority of the children (82.1\%) used to walk to school and from school. 110 (17.9\%) used public transportation to and from school. Nearly one fourth $(25.5 \%)$ of the children participated in sport activities, out of which 141 (88.7\%) performs for more than $30 \mathrm{~min}$. 274 (44.5\%) participated in doing an extra home activities. Nearly onefifth of school aged children (20.6\%) performed moderate physical activities.

Fifty eight $(9.4 \%)$ children used to play computer or mobile games. 527(85.6\%) used to watch television at home, around two-third (61.4\%) had watched TV more than $1 \mathrm{~h}$ per day (Tables 3 and 4).

\section{Anthropometric measurements and prevalence of overweight and obesity}

The mean weight $( \pm S D)$ and height $( \pm S D)$ of the surveyed children was $28( \pm 6)$ kilograms and $129.4( \pm 8.8)$ centimeters, respectively.

The overall prevalence of overweight/obesity using BMI for age cut off was found to be $11.9 \%$ (95\% CI: 9.3 , 14.4), out of which about 8.8 and $3.1 \%$ of children were overweight and obese, respectively. The proportion of overweight/obesity among private school children was $29.3 \%$, while in public schools it was $7 \%$. The sex specific proportion of overweight/obesity among male private and public school students was 26.9 and 5.6\%, respectively, and the proportion of overweight/obesity among
Table 2 Dietary habit of school children aged 6-12 years in Bahir Dar city northwest Ethiopia, $(n=616)$

\begin{tabular}{|c|c|c|}
\hline \multicolumn{3}{|l|}{ Characteristics' } \\
\hline Fruit and vegetable consumption & Frequency & Percentage (\%) \\
\hline Yes & 347 & 56.3 \\
\hline No & 269 & 43.7 \\
\hline \multicolumn{3}{|l|}{ Uses snack } \\
\hline Yes & 324 & 52.6 \\
\hline No & 292 & 47.4 \\
\hline \multicolumn{3}{|l|}{ Number of snacks/day } \\
\hline$\leq 2$ snacks/day & 166 & 51.2 \\
\hline$\geq 3$ snacks/day & 158 & 48.8 \\
\hline \multicolumn{3}{|l|}{ Number of meals/day } \\
\hline$<3$ meals/day & 23 & 3.7 \\
\hline$\geq 3$ meals/day & 593 & 96. \\
\hline \multicolumn{3}{|l|}{ Ways of getting lunch } \\
\hline Taking from home & 600 & 97.6 \\
\hline cafeteria/school Lounge & 16 & 2.4 \\
\hline \multicolumn{3}{|l|}{ Intake of fast food } \\
\hline Yes & 473 & 76.8 \\
\hline No & 143 & 23.2 \\
\hline \multicolumn{3}{|l|}{ Watching Television while eating } \\
\hline Yes & 285 & 46.3 \\
\hline No & 331 & 53.7 \\
\hline \multicolumn{3}{|l|}{ Eating while reading } \\
\hline Yes & 107 & 17.4 \\
\hline No & 509 & 82.6 \\
\hline \multicolumn{3}{|l|}{ Missing of meals } \\
\hline Yes & 268 & 43.5 \\
\hline No & 348 & 56.6 \\
\hline \multicolumn{3}{|c|}{ Access to restaurant/shop for fast food } \\
\hline Yes & 349 & 56.7 \\
\hline No & 267 & 43.3 \\
\hline
\end{tabular}


Table 3 Physical activity related behavior of school children aged 6-12 years in Bahir Dar city northwest Ethiopia 2016, $(n=616)$

\begin{tabular}{|c|c|c|}
\hline Characteristics & Number & Percentage (\%) \\
\hline \multicolumn{3}{|c|}{ Form of transport used for going to school } \\
\hline Walking & 506 & 82.1 \\
\hline Transportation & 110 & 17.9 \\
\hline \multicolumn{3}{|l|}{ Sport activity } \\
\hline Yes & 157 & 25.5 \\
\hline No & 459 & 74.5 \\
\hline \multicolumn{3}{|c|}{ Number minutes at sport activity } \\
\hline$<30 \min$ & 17 & 11.3 \\
\hline$\geq 30 \min$ & 140 & 88.7 \\
\hline \multicolumn{3}{|c|}{ Extra home activity } \\
\hline Yes & 274 & 44.5 \\
\hline No & 342 & 55.5 \\
\hline \multicolumn{3}{|c|}{ Doing an extra home activity } \\
\hline$<30 \min$ & 52 & 19.0 \\
\hline$\geq 30 \min$ & 222 & 81.0 \\
\hline \multicolumn{3}{|c|}{ Computer gamelmobile game } \\
\hline Yes & 58 & 9.4 \\
\hline No & 558 & 90.6 \\
\hline \multicolumn{3}{|c|}{ Time at computer \mobile game } \\
\hline$\leq 60 \min$ & 45 & 77.6 \\
\hline$>60 \mathrm{~min}$ & 13 & 22.4 \\
\hline \multicolumn{3}{|c|}{ Watching Television } \\
\hline Yes & 527 & 85.6 \\
\hline No & 89 & 14.4 \\
\hline \multicolumn{3}{|c|}{ Time at television/day } \\
\hline$<60 \min$ & 149 & 28.3 \\
\hline$\geq 60 \min$ & 378 & 71.7 \\
\hline \multicolumn{3}{|c|}{ Performing moderate activity } \\
\hline Yes & 127 & 20.6 \\
\hline No & 489 & 79.4 \\
\hline
\end{tabular}

female private and public school students was 31.43 and $8.18 \%$, respectively.

\section{Factors associated with overweight/obesity among school} aged children

The multivariable logistic regression analysis revealed that fruit and vegetable intake, household wealth status, type of school, physical activity, mode of transportation, fast food intake were significantly associated with overweight/obesity.

Accordingly, the odds of being overweight/obese were 6.5 times higher in children who had low fruits and vegetables consumption [AOR $=6.45,95 \% \mathrm{CI}$ : 3.19, 13.06].

Similarly, the higher likelihood of being overweight/ obese was found among children who belonged to the higher household wealth tertile compared to children from the lower tertile [AOR = 3.14, 95\% CI: 1.17, 8.46].

The higher odds of overweight/obesity were noted among children attending private schools compared to public school students $[\mathrm{AOR}=2.21,95 \% \mathrm{CI}$ : $1.09,4.49]$. Likewise, increased odds of overweight/obesity was observed among children who used transportation to and from school $[\mathrm{AOR}=2.53,95 \% \mathrm{CI}$ : $1.26,5.06]$ as well as those who did not perform moderate physical activity $[\mathrm{AOR}=, 2.87,95 \% \mathrm{CI} 1.21,6.82]$. The odds of being overweight/obesity were higher among children who had taken fast food compared to those children who didn't take fast food $[\mathrm{AOR}=3.88,95 \%$ CI 1.42, 10.55] (Table 5).

\section{Discussion}

This study revealed that $11.9 \%$ of school aged children are overweight/obesity with [95\% CI: 9.3, 14.4)]. This prevalence was consistent with the study done in Addis Ababa, Ethiopia (12.7\%) [15], and the study done in Sub-Saharan Africa countries (10.6\%) [10]. The finding of this study was also in the range of the study reports from Kenya in which $14.4 \%$ school children were overweight [32] and different parts of India, according to which about $4.9-12 \%$ of children were overweight and obesity [33-35].

This could be related to contextual similarities in change in dietary habit and lifestyle related to increased urbanization and nutrition transition. In addition, though there was a difference in age of the study participants between the current and the previous study settings, the similarity in the prevalence could be due to the fact that childhood overweight/obesity is one of the risk factors for adolescent overweight/obesity in low and middle income countries [16].

However, the prevalence of overweight/obesity was lower compared to the reports from other African countries, such as Dares Salaam, Tanzania (15\%) [11], Nairobi, Kenya 19\% [13], and Egypt (31.4\%) [9]. The discrepancy might be due to the disparities in study population and dietary habit.

Table 4 Prevalence of overweight and/obesity among school children in Bahir Dar city northwest Ethiopia, $2016(n=616)$

\begin{tabular}{llll}
\hline & Classification & Prevalence (\%) & Confidence interval \\
\hline Body mass index for age & Overweight & 8.8 & $6.5-11$ \\
& Obesity & 3.1 & $1.8-4.5$ \\
& Overweight/obesity & 11.9 & $9.3-14.4$ \\
\hline
\end{tabular}


Table 5 Factors associated with overweight/obesity among school children in Bahir Dar City North West Ethiopia, 2016, multivariable analysis $(n=616)$

\begin{tabular}{|c|c|c|c|c|}
\hline \multirow[t]{2}{*}{ Variables } & \multicolumn{2}{|c|}{ Overweight or obesity } & \multirow[t]{2}{*}{$\operatorname{COR}(95 \% \mathrm{Cl})$} & \multirow[t]{2}{*}{ AOR $(95 \% \mathrm{Cl})$} \\
\hline & Yes & No & & \\
\hline \multicolumn{5}{|c|}{ Maternal level of education } \\
\hline Secondary and above & 54 & 263 & $3.93(1.74,8.87)^{*}$ & $1.42(0.53,3.83)$ \\
\hline Primary & 12 & 146 & $1.57(0.60,4.11)$ & $1.24(0.42,3.69)$ \\
\hline No formal education & 7 & 134 & 1.0 & \\
\hline \multicolumn{5}{|c|}{ Husband/partner occupation } \\
\hline Private employed & 31 & 290 & $1.44(0.49,4.25)$ & $1.05(0.56,1.98)$ \\
\hline Formally employed & 38 & 199 & $2.58(0.88,7.54)^{*}$ & $1.90(0.52,6.89)$ \\
\hline Daily laborer & 4 & 54 & 1.00 & \\
\hline \multicolumn{5}{|l|}{ Fruit and vegetable intake } \\
\hline Yes & 11 & 336 & 1.00 & \\
\hline No & 62 & 207 & $9.15(4.71,17.78)^{* *}$ & $6.45(3.19,13.06)^{* *}$ \\
\hline \multicolumn{5}{|l|}{ Mode of transport } \\
\hline Walking/Bicycle & 38 & 468 & 1.00 & \\
\hline Transportation & 35 & 75 & $5.75(3.42,9.67)^{* *}$ & $2.53(1.26,5.06)^{*}$ \\
\hline \multicolumn{5}{|l|}{ Fast food intake } \\
\hline Yes & 68 & 405 & $4.63(1.83,11.73)^{*}$ & $3.88(1.42,10.55)^{*}$ \\
\hline No & 5 & 138 & 1.00 & \\
\hline \multicolumn{5}{|l|}{ Household wealth status } \\
\hline Low income & 7 & 199 & 1.00 & \\
\hline Middle income & 17 & 186 & $2.60(1.05,6.41)^{*}$ & $1.83(0.66,5.06)$ \\
\hline High income & 49 & 158 & $8.82(3.89,20.00)^{* *}$ & $3.14(1.17,8.46)^{*}$ \\
\hline \multicolumn{5}{|l|}{ Watching television } \\
\hline Do not watch TV & 3 & 86 & 1.00 & \\
\hline Watching For $<1 \mathrm{~h}$ & 5 & 144 & $1.00(0.23,4.27)$ & $0.45(0.10,2.11)$ \\
\hline Watching For $\geq 1 \mathrm{~h}$ & 65 & 313 & $5.95(1.83,19.41)^{*}$ & $1.65(0.45,6.10)$ \\
\hline \multicolumn{5}{|l|}{ Type of school } \\
\hline Public & 34 & 449 & 1.00 & \\
\hline Private & 39 & 94 & $5.48(3.29,9.13)^{* *}$ & $2.21(1.09,4.49)^{*}$ \\
\hline \multicolumn{5}{|l|}{ Missing meal } \\
\hline Yes & 38 & 230 & $1.48(0.91,2.41)$ & $1.11(0.61,2.01)$ \\
\hline No & 35 & 313 & 1.00 & \\
\hline \multicolumn{5}{|c|}{ Performing Moderate physical activity } \\
\hline Yes & 10 & 117 & 1.00 & \\
\hline No & 63 & 426 & $1.73(0.86,3.48)$ & $2.87(1.21,6.82)^{*}$ \\
\hline \multicolumn{5}{|l|}{ Age of the child } \\
\hline Age $<10$ years & 39 & 250 & $0.74(0.46,1.21)$ & $1.22(0.66,2.56)$ \\
\hline Age $\geq 10$ years & 34 & 293 & 1.00 & \\
\hline
\end{tabular}

Cl confidence interval, COR crude odds ratio, $A O R$ adjusted odds ratio

" $p$-value $<0.05 ;{ }^{* *} p$-value $<0.001$

Children who were from high income families were more likely to be overweight/obese as compared to low income families' children. This might be due to the fact that an increase in wealth status might shift high income families into nutrition transition by replacing traditional diet with energy dense diet and sedentary life style which are known risk factors of overweight/obesity [16]. 
Private school children's' were more likely to be overweight/obese as compared public school. This finding was supported by the findings of other studies that assessed children and adolescent's overweight/obesity in Tanzania, Kenya, Puerto Rico and India [8, 12, 13, 19, 36]. This might be due to the fact that in Ethiopia the public schools are funded by the government, where as private schools charge considerably higher tuition fees. Given that, only parents who can afford the fees would choose to enroll their children in private schools. We know that in developing countries children from high income families are more likely to have nutrition transition and sedentary behavior.

The odds of being overweight/obesity were higher among children who had taken fast food compared to those children who didn't take any fast food during the week. Similar findings were reported in Addis Ababa, London, and America [15, 20-22]; this might be related to the higher energy content of most of the fast foods.

Our study also indicated that low fruit and vegetable intake was associated with higher risk of being overweight/ obese. The finding was in agreement with the previous studies from Equatorial Guinea, London, Saudi Arabia $[20,22,23]$. This could be due to the fact that their bulk and low energy density of fruit and vegetable (with high amount of water and fiber) are believed to reduce energy dense food consumption and helps to easily attain satiety.

Children who used transportation to and from school were more likely to be overweight/obese than those who used to walk or to cycle to and from school. Similar findings are reported in Addis Ababa and Nigeria [15, 37]. It is known fact that the use of transportation leads to sedentary behaviour by decreasing energy expenditure. Children who had no moderate physical activities were more likely to become overweight/obese as compared to children who had performed moderate physical activities, which is supported by the previous studies [22, 37]. Physical activity determines number of calories that are spent or stored in the body as fat and maintains healthy weight status because of its potentially major impact on body composition, metabolism, and increasing energy expenditure.

\section{Study limitation}

Firstly, the study is not free from the pitfalls of cross sectional study design. Consequently, the result of the study didn't show the temporal cause and effect relationship between the outcome and the independent variables. Recall bias may be the second limitation of the study mainly in measuring the child's dietary habit and level of physical activity.

\section{Conclusion}

This study provided that Overweight/obesity among school aged children in Bahir Dar City is high. The result of an adjusted analysis showed that fruit and vegetable intake, household wealth status, type of school. Physical activity and mode of transportation were identified as the key determinants of overweight and obesity. Therefore, promoting a healthy life style such as improving fruit and vegetable intake and regular physical activity are essential. In addition, special attention needs to be given for children from high-income families and enrolled in private schools.

\section{Abbreviations}

AOR: Adjusted odds ratio; BMI: Body mass index; CDC: Center for diseases control and prevention; COR: Crude odds ratio; DALYs: Disability adjusted life years; DHS: Demographic Health survey; EDHS: Ethiopian Demographic Health Surveys; SD: Standard deviation; WHO: World Health Organization

\section{Acknowledgments}

We thank the study participants for volunteering to participate in this study, Bahir Dar city Administration Educational office; the data collectors for performing field work, Bahir Dar University School of Nursing for material support. We also gratefully acknowledge the financial support of university of Gondar Institute of Public Health.

\section{Funding}

This study was funded by University of Gondar. The views presented in the article are of the author and not necessarily express the views of the funding organization. University of Gondar were not involved in the design of the study, data collection, analysis, and interpretation.

\section{Availability of data and materials}

The datasets used and/or analyzed during the current study are available from the corresponding author on reasonable request.

\section{Authors' contributions}

TM conceived the study, coordinated the overall activity, and carried out the statistical analysis, drafted the manuscript, AT, SMA, participated in the design of the study, and reviewing the drafted the manuscript and approved the final manuscript. All authors read and approved the final manuscript.

\section{Ethics approval and consent to participate}

Ethical clearance was obtained from the Institutional Review Board of the University of Gondar. The supportive letter was obtained from Bahir Dar city administration educational office. Permission was obtained from each school director. During data collection, written informed consent was obtained from each child family after briefly explaining the purpose, risk, and benefit of the study. All the procedure and purpose were told to the child, and verbal assent was also obtained from each child before any data collection and Anthropometric measurements. Confidentiality of data was maintained by avoiding personal identifiers.

Consent for publication

Not applicable.

\section{Competing interests}

The authors declare that they have no competing interests.

\section{Publisher's Note}

Springer Nature remains neutral with regard to jurisdictional claims in published maps and institutional affiliations.

\section{Author details}

${ }^{1}$ Public Health Nutrition unit, School of Public Health, Bahir Dar University, P.O. Box 79, Bahir Dar, Ethiopia. ²Departments of Human Nutrition, Institute of Public Health, University of Gondar, P.O. Box 196, Gondar, Ethiopia. 
Received: 14 October 2017 Accepted: 9 January 2018

Published online: 23 January 2018

\section{References}

1. World Health organization: Obesity and overweight. 2016.

2. Ng M, Fleming T, Robinson M, Thomson B, Graetz N, Margono C, Mullany EC, Biryukov S, Abbafati C, Abera SF, et al. Global, regional, and national prevalence of overweight and obesity in children and adults during 1980 2013: a systematic analysis for the global burden of disease study 2013. Lancet. 2014;384:766-81.

3. de Onis M, Blossner M, Borghi E. Global prevalence and trends of overweight and obesity among preschool children. Am J Clin Nutr. 2010;92(5):1257-64.

4. Dennison ME, Sisson SB, Lora K, Stephens LD, Copeland KC, Caudillo C. Assessment of body mass index, sugar sweetened beverage intake and time spent in physical activity of American Indian children in Oklahoma. J Community Health. 2015;40(4):808-14.

5. Keane E, Kearney PM, Perry IJ, Kelleher CC, Harrington JM. Trends and prevalence of overweight and obesity in primary school aged children in the Republic of Ireland from 2002-2012: a systematic review. BMC Public Health. 2014;14(1):1.

6. dos Passos DR, Gigante DP, Maciel FV. Matijasevich a: Children's eating behavior: comparison between normal and overweight children from a school in Pelotas, Rio Grande do Sul, Brazil. Revista Paulista de Pediatria. 2015;33(1):42-9.

7. Gebremedhin S. Prevalence and differentials of overweight and obesity in preschool children in sub-Saharan Africa. BMJ Open. 2015;5(12):e009005.

8. Gupta N, Goel K, Shah P, Misra A. Childhood obesity in developing countries: epidemiology, determinants, and prevention. Endocrine Review. 2012;33(1):48-70

9. Manyanga T, El-Sayed H, Doku DT, Randall JR. The prevalence of underweight, overweight, obesity and associated risk factors among school-going adolescents in seven African countries. BMC Public Health. 2014;14:887.

10. Muthuri SK, Francis CE, Wachira L-JM, LeBlanc AG, Sampson M, Onywera VO, Tremblay MS. Evidence of an overweight/obesity transition among schoolaged children and youth in sub-Saharan Africa: a systematic review. PLoS One. 2014;9(3):e92846.

11. Muhihi AJ, Mpembeni R, Njelekela MA, Anaeli A, Chillo O, Kubhoja S, Lujani $B$, Maghembe M, Ngarashi D. Prevalence and determinants of obesity among primary school children in Dar es salaam, Tanzania. Arch Public Health. 2013;71(1):221-9.

12. Kimario JT. Prevalence of obesity and overweight among school children in Moshi municipality, Kilimanjaro, Tanzania, Masters thesis. Gent: Gent University; 2015

13. Kyallo F, Makokha A, Mwangi AM. Overweight and obesity among public and private primary school children in Nairobi, Kenya. Health. 2013;5(08):85.

14. Alebachew Z. Prevalence of childhood and adolescent overweight and obesity among elementary school students in Addis Ababa: double burden of malnutrition in Ethiopia. Ethiopia: Addis Ababa University; 2012.

15. Gebremichael B, Chere A. Prevalence of childhood overweight and obesity and its determinant factors among elementary school children in Addis Ababa, Ethiopia: a cross sectional study. Journal of Nutritional Disorders \& Therapy. 2015;2015

16. Tzioumis E, Adair LS. Childhood dual burden of under- and over-nutrition in low- and middle-income countries: a critical review. National Institute of Health. 2014;35(2):230-43.

17. Rivera JÁ, de Cossío TG, Pedraza LS, Aburto TC, Sánchez TG, Martorell R Childhood and adolescent overweight and obesity in Latin America: a systematic review. Lancet Diabetes Endocrinol. 2014;2(4):321-32.

18. Nishida C, Uauy R, Kumanyika S, Shetty P. The joint WHO/FAO expert consultation on diet, nutrition and the prevention of chronic diseases: process, product and policy implications. Public Health Nutr. 2004;7(1A): 245-50.

19. Elías-Boneta AR, Toro MJ, Garcia O, Torres R, Palacios C. High prevalence of overweight and obesity among a representative sample of Puerto Rican children. BMC Public Health. 2015;15(1):1.

20. Patterson R, Risby A, Chan MY. Consumption of takeaway and fast food in a deprived inner London borough: are they associated with childhood obesity? BMJ Open. 2012;2(3)

21. Dietz WH, Gortmaker SL. Preventing obesity in children and adolescents 1. Annu Rev Public Health. 2001;22(1):337-53.
22. Ebbeling CB, Pawlak DB, Ludwig DS. Childhood obesity: public-health crisis, common sense cure. Lancet. 360(9331):473-82.

23. Amin TT, Al-Sultan Al, Ali A. Overweight and obesity and their relation to dietary habits and socio-demographic characteristics among male primary school children in al-Hassa, Kingdom of Saudi Arabia. Eur J Nutr. 2008;47(6):310-8.

24. Koueta F, Dao L, Dao F, Djekompte S, Sawadogo J, Diarra Y, Kam K, Sawadogo A. Factors associated with overweight and obesity in children in Ouagadougou (Burkina Faso). Sante (Montrouge, France). 2010;21(4):227-31.

25. Birch LL, Fisher JO. Development of eating behaviors among children and adolescents. Pediatrics. 1998;101(Supplement 2):539-49.

26. Reilly JJ. Physical activity, sedentary behaviour and energy balance in the preschool child: opportunities for early obesity prevention. Proc Nutr Soc. 2008;67(03):317-25.

27. Amhara Regional Educational Office Reports on number of primary school children. 2015

28. World Health Organization. WHO STEPS surveillance manual : the WHO STEPwise approach to chronic disease risk factor surveillance / Noncommunicable Diseases and Mental Health. World Health Organization. 2005

29. Cogill B. Anthropometric indicators measurement guide. In: Food and nutrition technical assistance; 2003.

30. World health organization. WHO AnthroPlus for personal computers manual: software for assessing growth of the world's children and adolescents. Geneve: WHO; 2009.

31. Kuczmarski RJ, Ogden $\mathrm{CL}$, et al. "CDC growth charts: United States." Advance data 2000;(314):1-27.

32. Muthuri SK, Wachira L-JM, Onywera VO, Tremblay MS. Correlates of objectively measured overweight/obesity and physical activity in Kenyan school children: results from ISCOLE-Kenya. BMC Public Health. 2014;14(1):1.

33. Namdev G, Mishra MK, Saxena DMK, Ekka IJ, Likhar SK. Obesity among school children: an emerging threat in central india. Journal of Evolution of Medical and Dental Sciences. 2014;3(43):10634-10642.

34. Nayak BS. Prevalence of overweight/obesity among school children in Karnataka, South India. International Journal of Public Health Research. 2011:180-4.

35. Vohra R, Bhardwaj P, Srivastava JP, Srivastava S, Vohra A. Overweight and obesity among school-going children of Lucknow city. Journal of family and community medicine. 2011:18(2):59.

36. Bhardwaj S, Misra A, Khurana L, Gulati S, Shah P, Vikram NK. Childhood obesity in Asian Indians: a burgeoning cause of insulin resistance, diabetes and sub-clinical inflammation. Asia Pac J Clin Nutr. 2008;17(Suppl 1):172-5.

37. Alkali Y, Ambe J, Sabin M, Zacharin M. Socio-economic status, lifestyle and childhood obesity in Gombe. Nigerian Journal of Paediatrics. 2015:42(2):107-10.

\section{Submit your next manuscript to BioMed Central and we will help you at every step:}

- We accept pre-submission inquiries

- Our selector tool helps you to find the most relevant journal

- We provide round the clock customer support

- Convenient online submission

- Thorough peer review

- Inclusion in PubMed and all major indexing services

- Maximum visibility for your research

Submit your manuscript at www.biomedcentral.com/submit
) Biomed Central 